\title{
Appraising slow onset hazards for loss and damage: Case studies in Southeast Asia
}

Joy Jacqueline Pereira ${ }^{\text {a }}$, Juan Pulhin ${ }^{\text {, }}$, Nyda Chhinh ${ }^{c}$, Tran Dinh Trong d, and Siti Khadijah Satari ${ }^{\text {a }}$

\author{
a Southeast Asia Disaster Prevention Research Initiative (SEADPRI), Universiti Kebangsaan Malaysia, Bangi, Malaysia \\ $b$ University of The Philippines Los Baños, Los Baños, Philippines \\ c Royal University of Phnom Penh, Phnom Penh, Cambodia \\ d Viet Nam Institute of Meteorology, Hydrology and Climate Change, Hanoi, Viet Nam \\ * Corresponding author. Email: joy@ukm.edu.my
}

\section{ABSTRACT}

Slow onset processes were investigated in five pilot areas in Southeast Asia, i.e., Kampong Speu Province (Cambodia), Selangor State (Malaysia), Thatdama Kyun Village (Myanmar), Kanan Watershed (Philippines), and Quang Ngai Province (Vietnam). Pilot areas with low-lying coasts are exposed to floods, saline intrusion and sea-level rise while some are also affected by storms and typhoons. Floodplains are exposed to floods and river bank erosion while highlands are affected by flash floods, mudslides, landslides and forest degradation. Dry conditions and high temperatures are not confined to a specific geomorphological setting. The assessment of $\mathrm{L}+\mathrm{D}$ is a challenge as many impacts are not directly attributed to anthropogenic climate change. However, where science has clearly linked global warming and sea-level rise to anthropogenic causes, and human influence in a particular area is minimal, $\mathrm{L}+\mathrm{D}$ assessments are relevant to policy platforms such as the United Nations Framework Convention on Climate Change (UNFCCC). The land use planning system is a potential entry point for integrating DRR, CCA and L+D.

\section{KEYWORDS}

Climate change adaptation, Climate hazards, Disaster risk reduction, Loss and damage, Slow onset hazards, Southeast Asia

\section{DOI}

https://doi.org/10.30852/sb.2019.720

\section{DATES}

Received: 31 January 2019

Published (online): 23 July 2019

Published (PDF): 13 September 2019

\section{HIGHLIGHTS}

» Characteristics and issues on slow onset processes are context and area specific.

» Site features, capacity, resources and technology influence limits to adaptation.

" Detection and attribution to climate change is a major challenge for assessing $\mathrm{L}+\mathrm{D}$.

» The land use planning system facilitates integration of DRR, CCA and L+D.

» Integration is easier at the local level compared to a country-wide basis.

\section{INTRODUCTION}

The world is already seeing the consequences of $1^{\circ} \mathrm{C}$ of global warming through more extreme weather, rising sea-level and diminishing Arctic sea ice, among other changes (IPCC, 2018). A changing climate leads to changes in the frequency, intensity, spatial extent, duration and timing of extreme weather and climate events (IPCC, 2014). Extreme events may also trigger associated or cascading hazards depending on its nature, intensity, extent and locality. All types of fast and slow onset hazards are expected to increase as the climate changes. Ten key risks associated with fast and slow onset hazards have been identified for Asia, where a majority of these have direct impact on society in terms of health, well-being and safety (Hijioka et al., 2014). If global warming exceeds $1.5^{\circ} \mathrm{C}$, tropical Southeast Asia is projected to experience a range of fast and slow onset hazards that will impact economic growth (IPCC, 2018). 
Scientifically robust research is increasingly critical to document and report on loss and damage $(\mathrm{L}+\mathrm{D})$ due to climate impacts, particularly for Southeast Asia. It is also relevant to the Katowice Climate Package adopted in COP 24 in December 2018 (the Rule Book for the Paris Agreement), which gives prominence to $\mathrm{L}+\mathrm{D}$ in the upcoming global stock take.

Risk can be perceived as resulting from the interaction of climate hazards with vulnerability and exposure determined by socio-economic factors (IPCC, 2014). This understanding of risk facilitates the notion that the impacts of climate variability and change can be prevented; as they occur only in the intersection of hazard, vulnerability and exposure. The concept is important as it encourages focus on vulnerable groups and serves to drive adaptation efforts, particularly within national processes (van Aalst et al., 2018). It also promotes understanding that vulnerability and exposure cannot be totally removed, hence enabling the discourse on residual risks. However, there are limitations associated with this risk framework. The dynamic nature of risk, particularly the way it changes over time is not captured well. Furthermore, aspects related to capacity and underlying reasons for the inability of vulnerable groups to reduce climate-related risks or cope with impacts is not recognized.

The research project on "Integrating Climate Change Adaptation, Disaster Risk Reduction and Loss and Damage to Address Emerging Challenges due to Slow Onset Processes" brought together distinct groups of biophysical and socio-economic scientists. Key objectives included identification of characteristics, priorities and emerging issues related to slow onset processes in low-lying coastal areas, floodplains and highlands that impact the livelihood and well-being of the communities therein and assessment of the limits to adaptation based on "best available science", as well as approaches that integrate climate change adaptation (CCA) and disaster risk reduction (DRR). Other objectives include the development of methodologies to evaluate $\mathrm{L}+\mathrm{D}$ associated with adverse and cascading impacts of climate change drawing on lessons from disaster risk management, and discerning natural and anthropogenic causes of climate change. Ultimately, policy and planning strategies are recommended to integrate CCA, DRR and L+D in development plans in line with existing governance systems (APN, 2019).

In order to fulfill the project objectives, local level pilots were conducted in five countries in Southeast Asia (Cambodia, Malaysia, Myanmar, Philippines and Viet Nam) by teams of researchers from multidisciplinary backgrounds, working closely with their respective policy and decision-makers and local communities.
Researchers from Japan were also involved to facilitate transfer of knowledge and build capacity. Given the broad objectives of the project, this paper briefly describes the various slow onset processes and their features, which have been identified in each of the pilot areas. The challenge of managing hazards associated with these processes within each pilot is also highlighted. This is followed by a discussion on the limitation of the approach used in this project for loss and damage assessments, with respect to its relevance to ongoing discussions in policy platforms, specifically the United Nations Framework Convention on Climate Change (UNFCCC).

\section{METHODOLOGY}

Local level pilots were implemented in five countries, i.e., Kampong Speu Province (Cambodia), Selangor State (Malaysia), Thatdama Kyun Village (Myanmar), Kanan Watershed (Philippines) and Quang Ngai Province (Viet Nam). The assessment was conducted using the best available science from atmospheric, geological, chemical and social sciences, among others. Participatory appraisals were used to identify and rank local level hazards and processes. Questionnaire surveys and interviews were also carried out to supplement information related to L+D. Dialogues between researchers and policymakers of multi-disciplinary backgrounds were conducted on a periodic basis, to delineate effective options to integrate DRR and CCA in development plans. The risk framing approach was confined to specific geographic settings in this project. The spatial context was taken into account when demarcating zones with existing and future susceptibility to hazards, which was useful to delineate exposed elements and vulnerable communities. This area-based risk framing was used to investigate a range of fast and slow onset hazards in each pilot. This enabled risk to be perceived as a continuum, where DRR measures target short-term risks and CCA addresses long-term threats. This is also in line with the key message of IPCC (2014), which states that "the first step towards adaptation to future climate change is reducing vulnerability and exposure to present climate variability and associated extremes".

\section{RESULTS AND DISCUSSION}

Among theprojected impacts for Southeast Asiaunder global warming of $1.5^{\circ} \mathrm{C}$ include increases in the number of extreme hot days and heavy rains, which contribute to higher risks of floods, flash-floods and landslides as well as net reductions in yields and nutritional value of rice (IPCC, 2018). In addition, an increase is expected in populations that are both exposed and susceptible to 


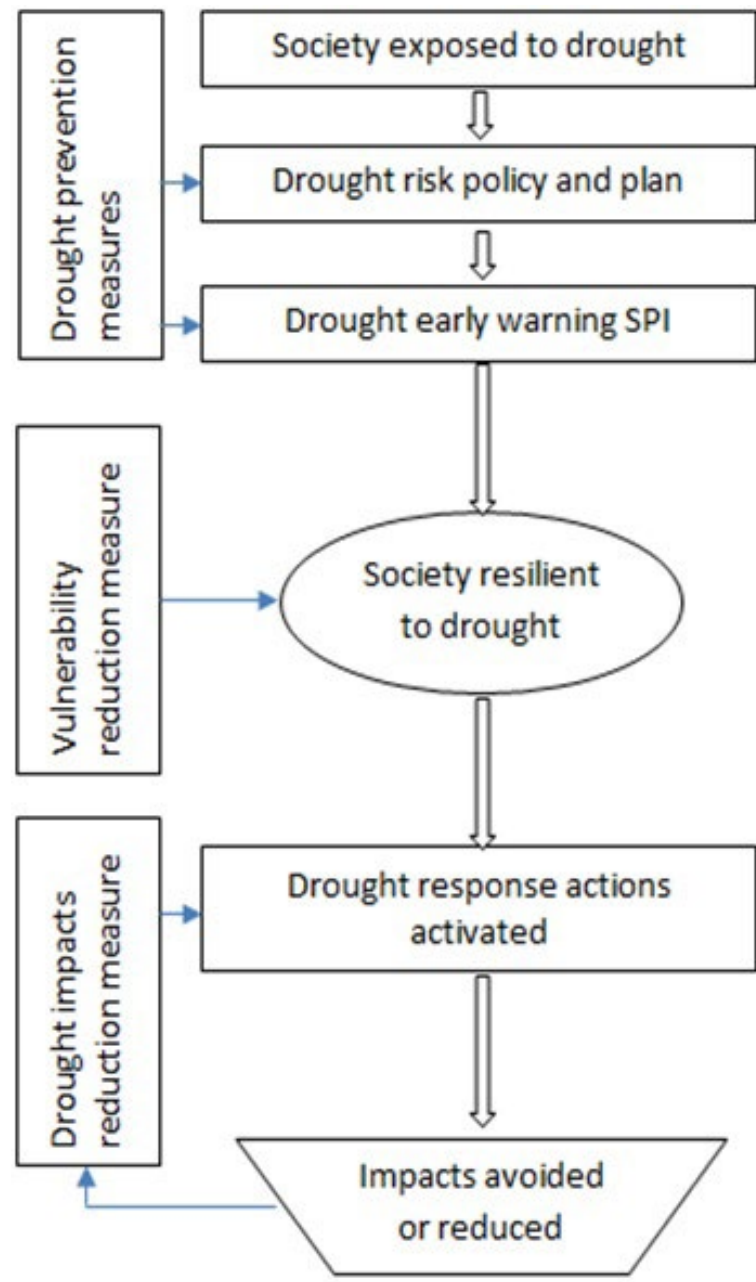

FIGURE 1. The drought risk management framework proposed for Cambodia mainstreams the involvement of exposed communities (Chhinh et al., 2019).

poverty, particularly those dependent on agriculture and coastal livelihood. As the sea level rises, low-lying coasts in Southeast Asia are expected to be affected, bringing new issues on environment and socio-economic aspects to the region, including those related to migration and security. Decision-makers have to be made aware of impending threats albeit with appropriate information on uncertainty (Doyle, Johnston, Smith, \& Paton, 2019).

\section{Slow Onset Processes in the Pilot Areas}

The Kampong Speu Province in Cambodia is located primarily within the catchment of the Prek Thnot River, with forests in the eastern highlands and agriculture in the western lowlands. Hazards common in the area are floods, drought and heatwaves. The slow onset characteristics of drought makes it difficult to detect as an emerging threat (Chhinh \& Millington, 2015). Drought requires effective water management within the affected community, who would be the first to experience the hazard. The response of the authorities at the national and local levels to drought has been relatively slow

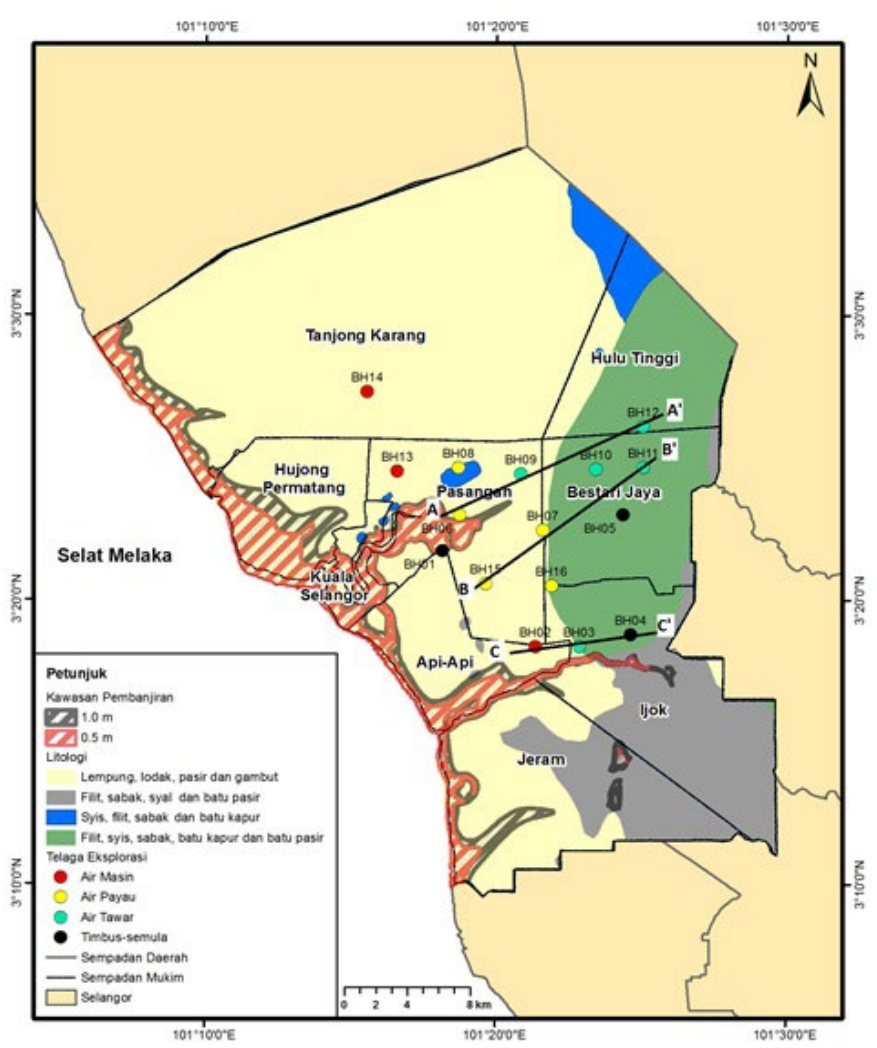

FIGURE 2. Coastal inundation susceptibility maps for two conditions, sea-level rise of $0.5 \mathrm{~m}$ (hatched in red) and $1.0 \mathrm{~m}$ (hatched in black), were used in conjunction with subsurface information from boreholes (colour coded circles) to determine the current quality of groundwater and its projected impacts (Umi et al., 2018).

compared to the actions taken to address floods. This indicates that it is important to build the capacity of the local community so that they can respond effectively while waiting for external support (Figure 1). Rainfall monitoring and forecasting, as well as effective irrigation systems, are major challenges for this agrarian community (Chhinh, 2014). This is compounded by disconnects between planning at the national and local levels, weak institutional arrangements and capacity, as well as poor engagement of all stakeholders, particularly the local community.

The Selangor State in Malaysia comprises a western coastal region that gets progressively more rugged to the east, where the highlands straddle part of the Titiwangsa Range. Kuala Selangor, the area that was studied in detail, is located in the coastal lowlands and is exposed to hazards such as coastal inundation, floods and saline intrusion due to sea-level rise (Umi, Yaakub, Suratman, \& Pereira, 2016). Agriculture areas in Kuala Selangor are susceptible to impacts of coastal inundation and saline intrusion, giving rise to future implications on food security as this is an important rice-production area (Figure 2). Saline intrusion is expected to affect sub-surface aquifers. Groundwater is affected in 


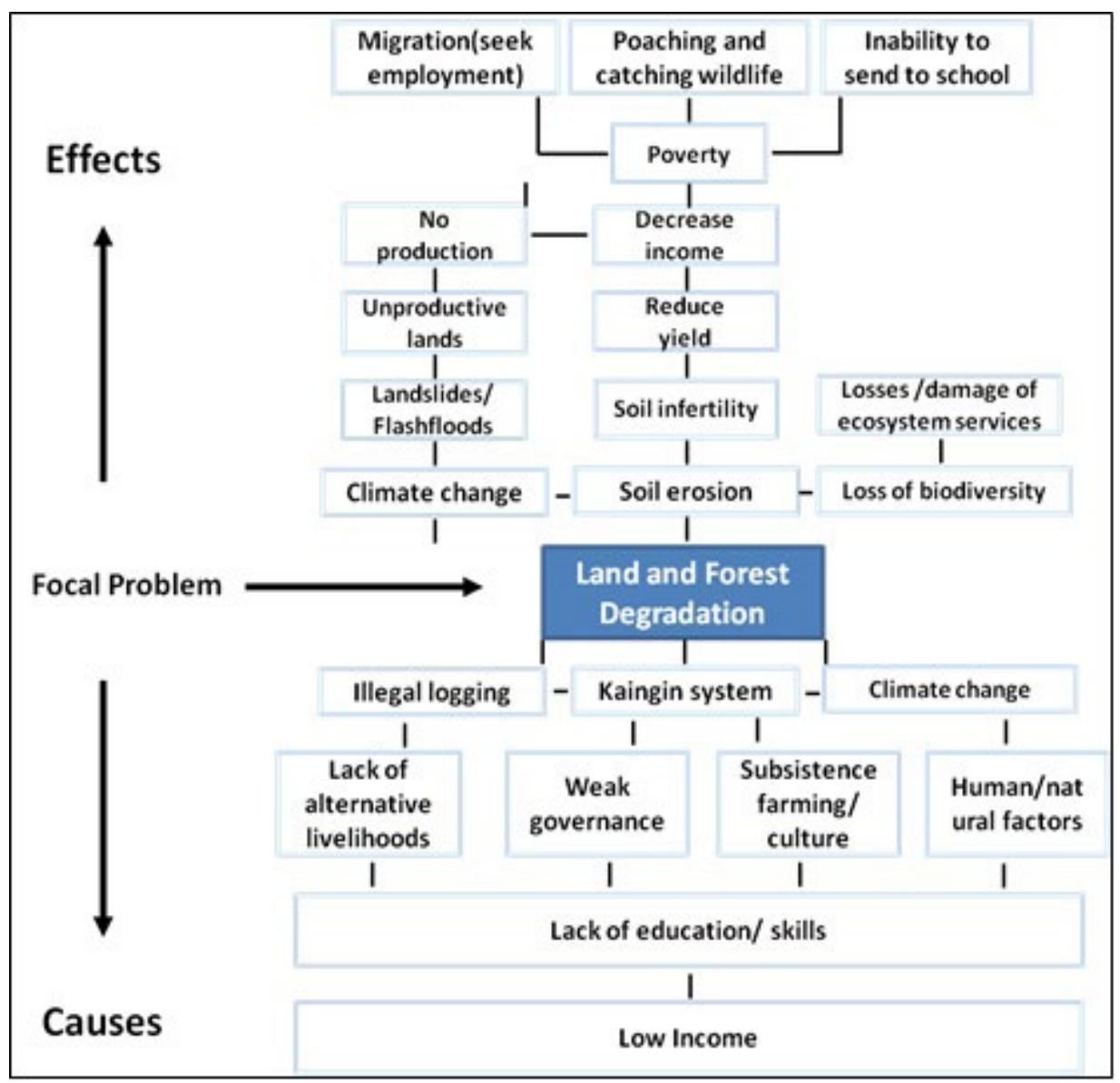

FIGURE 3. Local level focus group discussion resulted in the cause and effect diagram of land and forest degradation in the Kanan Watershed, General Nakar, Phillippines (Pulhin et al., 2019).

terms of both quality and quantity of reducing reserves for industrial, agricultural and domestic use (Umi, Lim, \& Pereira, 2018). An emerging hazard that has been detected in the Selangor State is the cascading effects of landfills and open dumps that are exposed to floods and landslides (Yahaya, Lim, Taha, \& Pereira, 2016). The rapid expansion of urban areas has brought residential zones closer to landfills and abandoned open dumps. Future disaster events may expose such population and make them vulnerable to emerging hazards. Preliminary assessment conducted on landfills and open dumps in Selangor reveals that six out of 20 landfill sites in the state are highly exposed to the 100-year flood, while two sites are exposed to slope failure (including mass waste movement). The exposed sites are currently without any protection measures making populated areas in the vicinity vulnerable to hazards and their cascading impacts. An integrated framework has been recommended in Kuala Selangor, building on existing policies such as the Integrated Coastal Zone Management (ICZM) and Environmental Impact Assessment (EIA). The integrated framework incorporates comprehensive and iterative adaptation, taking into account the natural state, projected conditions, potential impacts both at the surface and subsurface, deployment of science, technology and innovation, economic cost benefit analysis to identify suitable adaption options as well as continuous monitoring and evaluation, in conjunction with the local community, among others (Umi, Lim, \& Pereira, 2018).

The Thatdama Kyun Village in Myanmar is a landmass with changing morphology at the confluence of the Ayeyarwady and Pathein Rivers. The area is exposed to hazards such as flooding, river bank erosion, extreme temperature and irregular rainfall (SEEDS, 2019). The island setting of the village makes it prone to flooding and river bank erosion, which has damaged agriculture land, depleted livestock, reduced household income, affected food security, displaced village population and caused other social impacts. Heatwaves and an increasing number of hot days have caused health problems to the villagers. Vector and water borne diseases, as well as scarcity of drinking water, are also health issues of concern. While households receive weather-related information such as river level, wind speed and flood warnings from television and radio, the lack of electricity is a barrier to receive timely information on disasters. The lack of awareness has made it difficult for villagers to deal with the changes in climate and increased frequency of disasters. This is compounded by inherent vulnerability due to poor nutrition, health services and access to education. Enhanced capacity and technical information, as well as strengthened institutional frameworks, are critical to enable these villagers to manage the impacts of climate change (MoNRE, 2017).

The Kanan Watershed in the Philippines is a forestland drained by the Agos River with some 35 tributaries, stretching from the Sierra Madre Mountain to the Pacific Ocean. The area is exposed to flash floods, mudslides and landslides exacerbated by strong typhoons (Gaillard, Liamzon \& Villanueva, 2007). Flood waters that contaminate the local supply of drinking water resulting in increased cases of waterborne-diseases. Intense rainfall contributes to river siltation while increased temperatures dry up irrigation channels and other sources of water. Households in this area are vulnerable to land and forest degradation associated with climate change (Figure 3). Proactive interventions to raise awareness on the importance of the watershed and improvement 
of farming systems are important. Land and forest degradation has created cascading effects on infrastructure, agriculture, forestry and coastal sectors, among others (Social Action Center, 2014). This includes reduction in crop harvest by $30 \%$, reduced fish catch from rivers, loss of soil fertility due to soil erosion leading to low crop yields, damaged river canals and planted crops, decrease in water flow due to a month-long intense heat and loss of livelihood sources. Such events have contributed to economic and non-economic L+D in the area. Government and civil society organizations are providing assistance and support to communities in adapting to climate change and managing disasters (Local Government of General Nakar, DENR Region IV-A, \& the Haribon Foundation, no date). However, transformational adaptation (Warner et al., 2019) that addresses socio-economic and governance barriers are needed for present and future adaptation to be more effective.

The Quang Ngai Province in Viet Nam is a coastal province with diverse terrain with multiple fast and slow onset hazards. These include typhoons, tropical depressions, floods, flash floods, landslides, monsoons, thunderstorms, tornados, lightning, droughts, forest fires, saltwater intrusion and sea-level rise (Huynh, 2015). The management of drought is challenging and requires improvements in early warning and irrigation systems. Prolonged drought, in combination with high temperatures, creates a high risk of forest fires that destroy the environment on a large scale and seriously affects the microclimate (IMHEN \& UNDP, 2015). Sea-level rise and saltwater intrusion, which are typical slow onset processes, have been classified as low risk in the Province. The Ly Son Island is particularly sensitive to disasters and is most vulnerable to climate change (MoNRE, 2012). A vulnerability index developed at the national level based on parameters such as exposures, sensitivity and adaptive capacity was used to rank each district in Quang Ngai Province. This is to enable comparison between districts so that appropriate measures can be identified to build resilience to disasters and climate change. The priority for Quang Ngai Province is to increase resilience of the natural environment (Huynh, 2015). Loss and damage due to natural disasters is high in the Province.

\section{Challenges for Loss and Damage Assessment}

There are many approaches to assess L+D. These include accounting for economic and non-economic losses, and use of social media and crowdsourcing as well as and pre-defined economic costs to reduce assessment time during a disaster (Eckhardt, Leiras, \& Thome, 2019). However, the assessment of $\mathrm{L}+\mathrm{D}$ for slow-onset hazards remains a challenge. When deployed at the local level, the area-based risk framing approach does not differentiate impacts caused by natural or human induced climate change. In the UNFCCC platform, climate change is defined as change attributed to anthropogenic causes. This makes $\mathrm{L}+\mathrm{D}$ evaluation challenging in the pilot areas, where there is a paucity of data linking impacts to human-induced climate change. However, science has clearly linked global warming and sea-level rise to anthropogenic causes (IPCC (2014)). Drawing on this relationship, could heatwaves in Kampong Speu Province (Cambodia), Thatdama Kyun Village (Myanmar) and Quang Ngai Province (Viet Nam) be attributed to climate change? Forest fires in both these areas could not be directly attributed to climate change as the study could not differentiate human contribution from natural alteration. Similarly, could the expected impacts of global sea-level rise in Kuala Selangor (Malaysia), which includes coastal inundation and saline intrusion in a region with minimal groundwater extraction, be attributed to climate change? Where direct linkage has been proven in global conditions, as in the case of heatwaves and sea-level rise, and minimal human contribution is observed at the local level, $\mathrm{L}+\mathrm{D}$ assessments could and should be considered legitimate in the UNFCCC platform. In such areas, it is also possible to use historical socio-economic information to conduct a prospective $\mathrm{L}+\mathrm{D}$ evaluation. This can be done using multiple scenarios, including the worst case situation, where adaptation is absent.

\section{CONCLUSION}

The characteristics, priorities and emerging issues related to slow onset processes are context specific and area dependent. The local level pilot areas are exposed to multiple climate driven fast and slow onset hazards such as flood, landsides, drought, saline intrusion and forest degradation. Pilot areas with low-lying coastal areas are exposed to floods, saline intrusion and sea-level rise while some are also affected by storms and typhoons. Pilot areas in the floodplains are exposed to hazards such as floods and river bank erosion while the highland areas are affected by flash floods, mudslides, landslides and forest degradation. Some hazards are found to be independent of setting. These include dry conditions and high temperatures that trigger forest fires as well as landfills and open dumps that could become the source of emerging hazards.

Limits to adaptation are dependent upon the natural setting of an area, social capacity, resources and availability of technology. The area-based risk framing approach was useful to assess both fast and slow onset hazards in a specific area over a continuous time-frame. 
The short term requires DRR while the long term calls for CCA, when it is within natural limits. In Myanmar, the island setting of the Thatdama Kyun Village at the confluence of two rivers made it prone to flooding and river bank erosion. The loss of agriculture land, livelihood opportunity, health and other social issues have caused great hardship to the villagers and some have migrated away from the area. In Kuala Selangor, Malaysia, areas in the agriculture-rich lowlands will be exposed to slow onset coastal inundation, and saline intrusion is expected to affect sub-surface aquifers, giving rise to future food security issues. Some areas may have to be abandoned in the future, and it is important that the community is informed of this hazard and that resources are allocated for long term adaptation efforts. Increasing temperatures and heatwaves are already reported in the Kampong Speu Province (Cambodia), Thatdama Kyun Village (Myanmar) and Quang Ngai Province (Viet Nam). This hazard contributes to forest fires and impacts human health, and the situation is expected to worsen in Southeast Asia as global warming increases to $1.5^{\circ} \mathrm{C}$. The Governments of the region need to make comprehensive, coordinated efforts via ASEAN, the UNFCCC and other platforms to limit global warming below $1.5^{\circ} \mathrm{C}$. Resources should also be deployed in the region to adapt to a $1.5^{\circ} \mathrm{C}$ world.

The issue of detection and attribution to climate change is a major challenge in the assessment of $\mathrm{L}+\mathrm{D}$ for both fast and slow-onset hazards. The area-based risk framing approach used in this study assumes that all impacts are linked to anthropogenic climate change, which is not necessarily the case. There is limited evidence that any one single fast onset event is due to anthropogenic climate change. This makes $\mathrm{L}+\mathrm{D}$ assessments of such events a challenge, to be relevant to the UNFCCC platform. In the case of heatwaves and sea-level rise, where minimal human contribution is observed at the local level and direct links are proven in global conditions, $\mathrm{L}+\mathrm{D}$ assessments could provide significant contribution to the discourse at the UNFCCC platform. More scientific work is required from multi-disciplinary teams to develop a robust L+D methodology that incorporates detection and attribution to climate change, which is appropriate to the UNFCCC platform. A critical review of all research projects supported by APN and their ensuing publications, to delineate information on detection and attribution to climate change, would serve as an excellent foundation to advance $\mathrm{L}+\mathrm{D}$ assessment in the region.

Policy and planning strategies that integrate CCA, DRR and L+D are easier to deploy for specific local areas compared to a country-wide basis. The integration is also easier in small areas compared to large tracts of land, with a higher number of interacting hazards. The risk framing approach used in this study, which links DRR and CCA, can be expanded for a specific local area to include $\mathrm{L}+\mathrm{D}$. Historical $\mathrm{L}+\mathrm{D}$ information is useful to provide insights for developing prospective $\mathrm{L}+\mathrm{D}$ scenarios, both for DRR (near term) and CCA (long term). On a conceptual level, the three elements of DRR, CCA and L+D can be incorporated into land use planning and development management policies. The integrated framework should take into account fast and slow onset hazards and be suited to existing governance systems. Important aspects include natural state of the local area, projected conditions, potential impacts both at the surface and subsurface, deployment of science, technology and innovation, suitability of adaption options including transformative adaptation, as well as continuous monitoring and evaluation in conjunction with all stakeholders, especially the local community.

\section{ACKNOWLEDGMENTS}

The project thanks Dr S. V. R. K. Prabhakar and Mr Yohei Chiba of the Institute for Global Environmental Studies (IGES), Ms Natalia Derodofa of the Association of Southeast Asian Nations (ASEAN), Prof. Lord Julian Hunt of the Asian Network on Climate Science and Technology (ANCST), as well as Dr Raman Letchumanan and $\mathrm{Mr}$ Rocky Pairunan for facilitating the creation of synergies and optimization of resources through the organization of joint events. Researchers from collaborating institutions and key contributors, in particular SEEDS Asia (Prof. Rajib Shaw and Ms Mitsuko Otsuyama) are also gratefully acknowledged.

\section{REFERENCES}

APN (2019). Final Technical Report-Integrating Climate Change Adaptation (CCA), Disaster Risk Reduction (CCA) and Loss and Damage $(L+D)$ to Address Emerging Challenges due to Slow Onset Processes (CAF2016RRo3-CMY-Pereira). Kobe: Asia-Pacific Network for Global Change Research.

Chhinh, N. \& Millington, A. (2015). Drought monitoring for rice production in Cambodia. Climate, 3, 792-811.

Chhinh, N. (2014). Climate change adaptation in agriculture in Cambodia. In S. Vachani (Ed.), Adaptation to climate change in Asia (pp. 163-182). London, UK: Edward Elgar.

Doyle, E. E. H., Johnston, D. M., Smith, R. \& Paton, D. (2019). Communicating model uncertainty for natural hazards: A qualitative systematic thematic review. International Journal of Disaster Risk Reduction, 33, 449-476.

Eckhardt, D., Leiras, A. \& Thome, A. M. T. (2019). 
Systematic literature review of methodologies for assessing the costs of disasters. International Journal of Disaster Risk Reduction, 33, 398-416.

Gaillard, J. C., Liamzon, C. C. \& Villanueva, J. D. (2007). 'Natural' disaster? A retrospect into the causes of the late-2004 typhoon disaster in Eastern Luzon, Philippines. Environmental Hazards, 7:4, 257-270, DOI: 10.1016/j.envhaz.2006.11.002

Hijioka, Y., Lin E., Pereira, J. J., Corlett, R. T., Cui, X., Insarov, G. E., ... Surjan A. (2014). Asia. In V. R. Barros, C. B. Field, D. J. Dokken, M. D. Mastrandrea, K. J. Mach, T. E. Bilir, ... L. L. White (Eds.), Climate change 2014: Impacts, adaptation, and vulnerability. Part B: Regional aspects. Contribution of working group II to the fifth assessment report of the Intergovernmental Panel on Climate Change (pp. 1327-1370). Cambridge, United Kingdom: Cambridge University Press.

Huynh T. L. H. (2015). Scientific and technological research project: Research on climate change impacts for Quang Ngai Province; Adaptation and response measures. Vietnam Institute of Meteorology, Hydrology and Climate Change, Ministry of Natural Resources and Environment, Hanoi, Vietnam.

IMHEN \& UNDP (2015). Vietnam special report on managing the risks of extreme events and disasters to advance climate change adaptation. Hanoi, Vietnam: Vietnam Publishing House of Natural Resources Environment and Cartography.

IPCC (2014). Climate Change 2014: Synthesis Report. Contribution of Working Groups I, II and III to the Fifth Assessment Report of the Intergovernmental Panel on Climate Change (Core Writing Team, R. K. Pachauri and L. A. Meyer (Eds.). Geneva, Switzerland: Intergovernmental Panel on Climate Change.

IPCC (2018). Global Warming of $1.5^{\circ} \mathrm{C}$ : An IPCC Special Report. Geneva, Switzerland: Intergovernmental Panel on Climate Change.

Local Government of General Nakar, DENR Region IV-A, \& The Haribon Foundation (no date). General Nakar Forest Land Use Plan (FLUP) (2011-2016). General Nakar, Quezon Province.

MoNRE (2017). Myanmar climate change strategy and action plan (MCCSAP) 2016-2030 - 19th version draft. Ministry of Natural Resources and Environmental Conservation, Republic of the Union of Myanmar, Naypyidaw, Myanmar.

MoNRE (2012). Climate change scenarios, sea level rise for Vietnam. Hanoi, Vietnam: Vietnam Publishing House of Natural Resources - Environment and Cartography.

Chhinh, N., Nop, S. \& Thath, R. (2019). Case study of Kampong Speu Province, Cambodia. In Final Technical Report-Integrating Climate Change Adaptation (CCA),
Disaster Risk Reduction (CCA) and Loss and Damage $(L+D)$ to Address Emerging Challenges due to Slow Onset Processes (CAF2016-RRo3-CMY-Pereira). Kobe: Asia-Pacific Network for Global Change Research.

Pulhin, J. M., Sabino, L. L., Arnanza, A. B., Garcia, J. E., de Luna, C. C., Grefalda, L. B. \& Predo, C. D. (2019). Case study in Kanan Watershed, Philippines. In Final Technical Report-Integrating Climate Change Adaptation (CCA), Disaster Risk Reduction (CCA) and Loss and Damage $(L+D)$ to Address Emerging Challenges due to Slow Onset Processes (CAF2016-RRo3-CMYPereira). Kobe: Asia-Pacific Network for Global Change Research.

SEEDS (2019). Case study of Thatdama Kyun Village, Myanmar. In Final Technical Report-Integrating Climate Change Adaptation (CCA), Disaster Risk Reduction (CCA) and Loss and Damage $(L+D)$ to Address Emerging Challenges due to Slow Onset Processes (CAF2016-RRo3-CMY-Pereira). Kobe: Asia-Pacific Network for Global Change Research.

Social Action Center (2014). Community based early warning system along the Agos River in Infanta and General Nakar, Quezon Province, Philippines.

Umi, A. J., Lim, C. S. \& Pereira, J. J. (2018). Implikasi perubahan iklim terhadap zon pesisir pantai di Kuala Selangor, Malaysia. Bulletin of the Geological Society of Malaysia, 66, 107-119.

Umi, A. J., Yaakub, J., Suratman, S., \& Pereira, J. J. (2016). Threats faced by groundwater: A preliminary study in Kuala Selangor. Bulletin of the Geological Society of Malaysia, 62, 65-72.

van Aalst, M., Jones, R., Lavell, A., Pörtner, H., Roberts, D., Tall, A., ... \& Warrick, O. (2018). Bridging Climate Science, Policy and Practice. Report of the International Conference on Climate Risk Management, Pre-Scoping Meeting for the IPCC Sixth Assessment Report. Red Cross Red Crescent Climate Centre, The Hague, The Netherlands.

Warner, K., Zommers, Z., Wreford, A., Hurlbert, M., Viner, D., Scantlan, J., ... \& Tamang, C. (2019). Characteristics of transformational adaptation in climate-land-society interactions. Sustainability, 11(2), 356.

Yahaya, N. S., Lim, C. S., Taha, M. R., \& Pereira, J. J. (2016). Exposure of municipal solid waste disposal sites to climate related geohazards: Case study of Selangor. Bulletin of the Geological Society of Malaysia, 62, 57-63. 